\title{
INCENTIVES FOR SABOTAGE
}

\section{IN VERTICALLY-RELATED INDUSTRIES}

by

\author{
David M. Mandy* and David E. M. Sappington**
}

\begin{abstract}
We show that the incentives a vertically integrated supplier may have to disadvantage or "sabotage" the activities of downstream rivals vary with both the type of sabotage and the nature of downstream competition. Cost-increasing sabotage is typically profitable under both Cournot and Bertrand competition. In contrast, demand-reducing sabotage is often profitable under Cournot competition, but unprofitable under Bertrand competition. Incentives for sabotage can vary nonmonotonically with the degree of product differentiation.
\end{abstract}

* University of Missouri.

** University of Florida.

This research emanated from collaborative discussions with Dennis Weisman. We are grateful to Dennis for his many useful suggestions regarding this paper and our research efforts more generally. We also thank Yossi Spiegel and an anonymous referee for helpful comments. 


\section{Introduction.}

In many important industries, regulated suppliers of essential upstream products are capable of operating in unregulated downstream markets. For example, in the telecommunications industry, the Regional Bell Operating Companies (RBOCs) supply access to the local telecommunications network, and they could deliver long distance telephone service if they were permitted to do so. Until recently, though, regulators have forbidden the RBOCs from providing long distance telephone service. ${ }^{1}$ A primary rationale for this prohibition is that it prevents the RBOCs from engaging in activities that unduly favor their long distance affiliates at the expense of their downstream rivals. Such activities include: (1) providing inferior service to competitors, perhaps in part by increasing the relative frequency with which their calls are blocked (Bernheim and Willig, 1996, p. 4.10); (2) delaying competitors' attempts to implement new and improved services (Economides, 1998; Kang and Weisman, 2001); (3) withholding crucial information from competitors about how they might best utilize the network to provide valued services to their customers (Bernheim and Willig, 1996, p. 4.10; Economides, 1998); and (4) structuring services and standards to favor the operations of their downstream affiliates at the expense of rivals (Bernheim and Willig, 1996, p. 4.6; Beard et al., 2001).$^{2}$

The economic literature refers to activities of this sort that disadvantage downstream rivals as sabotage, and typically assumes that sabotage serves to raise the operating costs of downstream rivals. The literature concludes that by raising the costs of downstream rivals, sabotage generally increases the profit of the downstream affiliate of the vertically integrated producer. This is the case

1. In December 1999, Verizon became the first RBOC to secure permission to provide in-region long distance (i.e., interLATA) service (in New York State). SBC followed suit (in Texas) in June 2000. As of January 1, 2003, the RBOCs had received permission to provide in-region interLATA service in thirty-five states. (http://www.fcc.gov/Bureaus/Common_Carrier/in-region_applications.)

2. Similar concerns led to the divestiture of the Bell System in 1984. See, for example, Faulhaber (1987, p. 84). 
whether downstream suppliers engage in Cournot (quantity-setting) competition (e.g., Economides, 1998; Sibley and Weisman, 1998b; Bustos and Galetovic, 2003) or Bertrand (price-setting) competition (e.g., Weisman, 1995; Beard et al., 2001; Kondaurova and Weisman, 2003). ${ }^{3}$ The literature also notes, though, that by inducing downstream rivals to reduce their output, costincreasing sabotage can decrease demand for the upstream product (e.g., access to the telecommunications network), and thereby reduce upstream profit when the price of the upstream product exceeds its marginal cost of production (Weisman, 1995; Sibley and Weisman, 1998, 1999; Kang and Weisman, 2001). Thus, the literature suggests that because cost-increasing sabotage generally increases the downstream profit and reduces the upstream returns of the vertically integrated supplier, the likelihood of sabotage in practice is an empirical matter that merits investigation on an industry-by-industry basis. ${ }^{4}$

The primary purpose of our research is to demonstrate that these qualitative conclusions do not necessarily hold when sabotage serves to reduce rivals' demands rather than raise rivals' costs. Although some forms of sabotage (e.g., engaging in protracted litigation and imposing standards that are particularly costly for rival producers to adopt) may increase rivals' operating costs, other forms of sabotage (e.g., degrading the relative quality of competitors' products and limiting the ability of competitors to test new products and deliver them to customers) may primarily reduce the demand for rivals' products. We show that in plausible settings, a vertically integrated supplier will choose not to undertake demand-reducing sabotage, even though it will implement cost-increasing sabotage.

Another purpose of this research is to show that the potential gains from sabotage vary not only

3. Kang and Weisman (2001) examine both Cournot and Bertrand competition. Mandy (2000) provides a review of the literature.

4. See Mandy (2000), Kang and Weisman (2001), Weisman and Williams (2001), and Kondaurova and Weisman (2003) for examples of such industry-specific investigations. This countervailing upstream effect of downstream sabotage is one key difference between this literature and the earlier literature on raising rivals' costs (e.g., Salop and Scheffman, 1983, 1987). 
with the type of sabotage, but also with the nature of downstream competition. We show that demand-reducing sabotage typically functions much like cost-increasing sabotage under downstream Cournot competition..$^{5}$ In this setting, both demand-reducing and cost-increasing sabotage induce rivals to reduce their output levels. Reduced rival output increases the demand for the downstream product of the vertically integrated supplier, and thereby increases its downstream profit. Aggregate downstream output can fall, however, and thereby reduce the demand for upstream access, and hence, upstream profit. Consequently, the vertically-integrated supplier must weigh these countervailing effects when determining its preferred level of demand-reducing sabotage under downstream Cournot competition. The downstream price increases induced by cost-increasing sabotage under Bertrand competition give rise to similar countervailing effects.

In contrast, demand-reducing sabotage can give rise to very different effects under Bertrand competition. By reducing the demand for rivals' products, the sabotage induces rival downstream firms to reduce the prices they charge for their products. That is, rivals respond aggressively under Bertrand competition, in contrast to their accommodating behavior under Cournot competition. The rivals' price reductions under Bertrand competition, in turn, reduce the demand for the downstream product of the integrated supplier, and thereby reduce its downstream profit. And unless the quantity responses to the induced downstream price reductions more than offset the direct reduction in downstream output caused by sabotage, demand for the upstream product also declines, which typically reduces upstream profit. Consequently, the integrated supplier usually refrains from demand-reducing sabotage in the presence of downstream Bertrand competition.

The formal derivation of our findings begins in section 2 , where we examine the integrated

5. In this regard, our findings are consistent with those of Cremér et al. (2000). The authors analyze a model in which Internet backbone providers choose their capacity levels and the quality of their interconnection with other backbone providers. The authors demonstrate that large providers typically prefer to implement lower interconnection qualities because doing so reduces differentially the value of the services that smaller rivals can deliver to their customers. 
supplier's incentives for sabotage when downstream producers engage in Cournot competition. The corresponding incentives for sabotage when downstream firms engage in Bertrand competition are analyzed in section 3. In section 4, linear versions of the models are analyzed to determine how incentives for sabotage vary with the degree of product differentiation. We identify plausible conditions under which the incentives for sabotage increase systematically as products become more homogeneous. ${ }^{6}$ However, we also demonstrate that sabotage does not always vary monotonically with the degree of product homogeneity.

This research concludes in section 5, where we discuss the implications of our findings and directions for future research. We emphasize that our finding that demand-reducing sabotage is often unprofitable does not imply that the potential for sabotage should be ignored when designing public policy toward vertical integration in regulated industries. ${ }^{7}$ Instead, our findings help to identify the types of sabotage that may be most problematic in practice and the industry conditions under which the incentives for sabotage are likely to be most pronounced.

\section{Cournot Competition.}

First consider the setting in which the downstream firms engage in Cournot (quantity-setting) competition. For simplicity, we analyze duopoly competition between the downstream affiliate of the integrated producer and an unaffiliated rival. The rival's fixed cost of production is denoted $F^{r} \geq 0$, and its constant marginal cost of production (absent any cost-increasing sabotage and

6. As products become more homogeneous, the downstream division of the integrated firm is able to satisfy more of the customer demand that is displaced by cost-increasing or demand-reducing sabotage. This effect ensures that sabotage provides larger downstream gains and smaller upstream losses for the integrated firm under some conditions, and so will be pursued more vigorously.

7. Although our formal analysis considers the setting where a regulator sets the price charged by a monopoly upstream producer, our basic qualitative conclusions have broader relevance. As Economides (1998), Mandy (2000), and others point out, concerns about potential sabotage arise in many industries, including the computer software industry. 
abstracting from the cost of the upstream input) is denoted $c^{r} \geq 0$. The corresponding fixed and marginal costs of the downstream affiliate of the integrated firm (hereafter the affiliate) are denoted $F^{d} \geq 0$ and $c^{d} \geq 0$, respectively. All fixed costs are assumed to be sunk costs.

One unit of the upstream product (e.g., access to the local telephone network) is required for each unit of the downstream product (e.g., long distance telephone calls) that is produced. The upstream product, called access, is produced by the upstream division of the integrated firm at constant marginal cost $c^{u} \geq 0$, after fixed cost $F^{u} \geq 0$ is incurred. The upstream producer supplies all of the access that is demanded by the downstream producers at the regulated access price $a \geq c^{u} .^{8}$

In addition to supplying access, the upstream firm may undertake cost-increasing sabotage $\left(s^{c}\right)$, demand-reducing sabotage $\left(s^{q}\right)$, or both. Each unit of cost-increasing sabotage increases the rival's marginal cost by one unit. Demand-reducing sabotage systematically reduces the demand for the rival's product in the manner described below. $K\left(s^{c}, s^{q}\right)$ denotes the direct cost incurred by the upstream producer when it undertakes $s^{c}$ units of cost-increasing sabotage and $s^{q}$ units of demand-reducing sabotage. In practice, the direct costs of sabotage might include extra litigation or engineering expenses, or penalties that are incurred if sabotage is detected by regulators, for example. ${ }^{9}$ The costs of sabotage are assumed to be non-negative and to increase with the level of

8. We follow both the literature and common practice by examining uniform, non-discriminatory access prices. We assume the access price exceeds the upstream marginal cost of production for expositional convenience. The qualitative changes that would arise if access were priced below cost will become apparent as we proceed. Notice in particular that upstream profit increases as the demand for access declines when $a<c^{u}$. By focusing on the setting where $a \geq c^{u}$, we avoid this (obvious and largely uninteresting) reason for sabotaging rivals' operations.

9. Section 271(d)(6) of the Telecommunications Act of 1996 (Pub. L. No. 104-104, 110 Stat. 56 (codified at scattered sections of 47 U.S.C.)) empowers the Federal Communications Commission to penalize a Bell operating company that is found to have discriminated against a competing supplier of interLATA services. Possible penalties include a monetary fine and suspension or revocation of the Bell operating company's right to provide interLATA services. 
sabotage at a non-decreasing rate (i.e., $K\left(s^{c}, s^{q}\right) \geq 0, K_{i}(\cdot) \geq 0$, and $K_{i i}(\cdot) \geq 0$ for $i=1,2$, where the subscript $i$ (here and throughout) denotes the partial derivative with respect to the $i^{\text {th }}$ argument of the function. ${ }^{10,11}$

$P^{d}\left(q^{d}, q^{r}\right)$ denotes the maximum price the affiliate can charge and still sell $q^{d}$ units of output when the rival sells $q^{r}$ units of output. $P^{r}\left(q^{r}, q^{d}, s^{q}\right)$ denotes the corresponding maximum price the rival can charge and still sell $q^{r}$ units of output when the affiliate sells $q^{d}$ units of output and the upstream firm has undertaken $s^{q}$ units of demand-reducing sabotage. The maximum price that each firm can charge for its product is a decreasing function of its own output (so $P_{1}^{i}(\cdot)<0$ when $P^{i}(\cdot)>0$ and $q^{i}>0$, for $\left.i=d, r\right)$. Furthermore, the products of the two downstream operators are gross substitutes, so $P_{2}^{i}(\cdot)<0$ for $i=d, r$. In addition, demand-reducing sabotage reduces the maximum price the rival can set for all output levels (i.e., $\left.P_{3}^{r}(\cdot)<0\right){ }^{12}$

When the affiliate and the rival sell $q^{d}$ and $q^{r}$ units of output, respectively, and when the upstream producer undertakes $s^{c}$ and $s^{q}$ units of cost-increasing and demand-reducing sabotage, respectively, upstream profit, $\pi^{u}(\cdot)$, is:

$$
\pi^{u}\left(q^{d}, q^{r}, s^{c}, s^{q}\right)=\left[a-c^{u}\right]\left[q^{d}+q^{r}\right]-F^{u}-K\left(s^{c}, s^{q}\right) .
$$

The corresponding downstream profit of the affiliate, $\pi^{d}(\cdot)$, is:

$$
\pi^{d}\left(q^{d}, q^{r}, s^{c}, s^{q}\right)=\left[P^{d}\left(q^{d}, q^{r}\right)-c^{d}-a\right] q^{d}-F^{d}
$$

and the corresponding profit of the rival, $\pi^{r}(\cdot)$, is:

10. As Reiffen (1998) points out, higher levels of sabotage could reduce upstream operating costs. When this is the case, sabotage will offer benefits to the upstream firm in addition to those that we identify below. We abstract from these considerations for expositional simplicity, although we will often consider the benchmark setting where sabotage is not costly (so $K\left(s^{c}, s^{q}\right)=0$ for all $s^{c}, s^{q}>0$ ).

11. Here and throughout the ensuing discussion, stated inequalities are assumed to hold for all values of the relevant variables, unless otherwise noted.

12. To ensure compact strategy spaces, we presume that $P^{d}\left(q^{d}, 0\right)=0$ at some finite $q^{d}>0$ and $P^{r}\left(q^{r}, 0,0\right)=0$ at some finite $q^{r}>0$. 


$$
\pi^{r}\left(q^{r}, q^{d}, s^{c}, s^{q}\right)=\left[P^{r}\left(q^{r}, q^{d}, s^{q}\right)-c^{r}-a-s^{c}\right] q^{r}-F^{r}
$$

$\pi^{I}\left(q^{d}, q^{r}, s^{c}, s^{q}\right)=\pi^{d}(\cdot)+\pi^{u}(\cdot)$ denotes the total profit of the integrated firm.

We focus on the case in which the upstream and downstream divisions of the integrated firm seek to maximize the firm's total profit. ${ }^{13}$ In this case, after the upstream firm observes the regulated access price, it implements the amount of sabotage that maximizes $\pi^{I}(\cdot)$, anticipating the downstream activity to follow. After observing the access price and the established levels of sabotage, the downstream producers select their output levels noncooperatively and simultaneously. The affiliate chooses $q^{d}$ to maximize $\pi^{I}(\cdot)$, and the rival chooses $q^{r}$ to maximize $\pi^{r}(\cdot)$. The chosen quantity levels constitute a Nash equilibrium. After the quantities are set, market-clearing prices are established, outputs are sold, and profits are realized. This interaction is not repeated.

We adopt the standard assumption that downstream quantities are strategic substitutes (so $\pi_{12}^{i}(\cdot)<0$ for $\left.i=I, r\right) .{ }^{14}$ This assumption ensures that an increase in the output of one firm reduces the marginal return from increased output to the other firm or, equivalently, increases the marginal return from decreased output to the other firm. Consequently, the subgame in which the affiliate chooses $q^{d}$ and the rival chooses $-q^{r}$ is supermodular (Topkis, 1995; Milgrom and Roberts, 1990; Vives, 1999, pp. 32-34). Therefore, if increases in sabotage systematically reduce the rival's incremental return from expanded output (i.e., if $\pi_{13}^{r}\left(q^{r}, q^{d}, s^{c}, s^{q}\right) \leq 0$ and $\pi_{14}^{r}(\cdot) \leq 0$ for all $\left.q^{r}, q^{d}, s^{c}, s^{q}\right)$, higher levels of sabotage will reduce the rival's equilibrium

13. In practice, vertically integrated producers are sometimes required to conduct their downstream operations through a separate subsidiary. A separate subsidiary may value its own profit more highly than it values the profit of the integrated firm. Our main qualitative conclusions are readily shown to persist in such a setting. We provide further thoughts on this issue in the concluding section.

14. See Bulow et al. (1985). A sufficient condition for quantities to be strategic substitutes in the present setting is that $P_{12}^{i}(\cdot) \leq 0$ for $i=d, r$, so that the inverse demand curve facing each firm becomes steeper as its opponent's output increases. 
output and increase the affiliate's equilibrium output (Vives, 1999, p. 35). ${ }^{15}$

Higher levels of cost-increasing sabotage always reduce the rival's return from expanded output by increasing the rival's marginal cost of production $\left(\pi_{13}^{r}(\cdot)=-1\right)$. Increased demand-reducing sabotage will also reduce the rival's return from expanded output if the increased sabotage does not decrease the sensitivity of the rival's price to its output. Formally, assumption (A2.1) is sufficient to ensure $\pi_{14}^{r}(\cdot) \leq 0$.

Assumption (A2.1). $\quad P_{13}^{r}\left(q^{r}, q^{d}, s^{q}\right) \leq 0$.

When assumption (A2.1) holds, demand-reducing sabotage shifts the rival's inverse demand curve inward and makes it steeper. Both effects render a lower output optimal for the rival.

The effects of increased sabotage on equilibrium output levels are summarized in Lemma 2.1. ${ }^{16}$

Lemma 2.1. Under downstream Cournot competition:

(i) the affiliate's equilibrium output is non-decreasing and the rival's equilibrium output in nonincreasing in the level of cost-increasing sabotage; and

(ii) the affiliate's equilibrium output is non-decreasing and the rival's equilibrium output is nonincreasing in the level of demand-reducing sabotage if assumption (A2.1) holds. More generally, the effects of increased demand-reducing sabotage on downstream quantities are ambiguous. $^{17}$

15. The effects of sabotage on the incremental return of the integrated firm need not be considered because neither sabotage parameter enters $\pi_{1}^{I}(\cdot)$. The same is not true in the Bertrand analysis of section 3.

16. It follows from Vives (1999, pp. 33-34) that an equilibrium exists in the setting under consideration. If the equilibrium is not unique, the conclusions in Lemma 2.1 (and all ensuing formal conclusions) pertain to the extremal equilibria (Vives, 1999, pp. 34-35).

17. It can be shown that the equilibrium in the Cournot subgame will be unique under the maintained assumptions if, in addition, the inverse demand curves are concave in own quantities, equal increases in both downstream outputs render each competitor's price more sensitive to its own output, and ownprice effects outweigh cross-price effects (i.e., if $P_{11}^{i}(\cdot) \leq 0, P_{11}^{i}(\cdot) \leq P_{12}^{i}(\cdot)$, and $P_{1}^{i}(\cdot) \leq P_{2}^{i}(\cdot)$ for $i=d, r)$. When the Cournot equilibrium is unique and interior: (i) the equilibrium output of the 
Lemma 2.1 reports an unambiguous impact of cost-increasing sabotage on downstream outputs. By raising the rival's operating costs, cost-increasing sabotage induces the rival to reduce its output. The reduction in the rival's output shifts outward the affiliate's demand curve. In response, the affiliate increases its output.

In contrast, the impact of demand-reducing sabotage is ambiguous in general. Because it shifts the rival's inverse demand curve inward, one effect of demand-reducing sabotage is to encourage the rival to reduce its output. A countervailing effect is also possible, though. If demand-reducing sabotage renders the rival's inverse demand curve less steep, so that a smaller price reduction is required to sell any given increase in output, the rival may prefer to expand its output. However, if demand-reducing sabotage shifts the rival's inverse demand curve inward and makes it more steep (as when assumption (A2.1) holds), demand-reducing sabotage will induce the rival to reduce its output by unambiguously reducing the marginal value of increased output to the rival. This reduction in the rival's output shifts the affiliate's demand curve outward. In response to the increase in the demand for its product, the affiliate increases its output.

When sabotage induces the rival to reduce its output, the resulting increase in demand for the affiliate's product ensures higher downstream profit for the affiliate in standard fashion (e.g., Dixit, 1986; Vives, 1999, p. 102). Therefore, absent upstream effects, cost-increasing sabotage always increases the profit of the integrated firm, as does demand-reducing sabotage that does not decrease the sensitivity of the rival's price to its output. These conclusions are recorded formally as Propositions 2.1 and 2.2. Upstream effects are said to be absent when the upstream profit margin is zero (so $a=c^{u}$ ) and sabotage is not costly (so $K\left(s^{c}, s^{q}\right)=0$ for all $s^{c}, s^{q} \geq 0$ ).

affiliate strictly increases and the rival's equilibrium output strictly decreases as cost-increasing sabotage increases; and (ii) the affiliate's equilibrium output strictly increases and the rival's equilibrium output strictly decreases as demand-reducing sabotage increases if assumption (A2.1) holds. These conclusions can be proved using conventional comparative static analysis (Mandy and Sappington, 2001). 
Proposition 2.1. When upstream effects are absent and the downstream competitors engage in

Cournot competition, the upstream producer will undertake cost-increasing sabotage.

Proposition 2.2. When upstream effects are absent, assumption (A2.1) holds, and the downstream competitors engage in Cournot competition, the upstream producer will undertake demandreducing sabotage.

Upstream effects need not be entirely absent to ensure that sabotage will arise in equilibrium.

As long as the direct costs of initial increments in sabotage $\left(K_{1}\left(0, s^{q}\right)\right.$ and $\left.K_{2}\left(s^{c}, 0\right)\right)$ and the upstream profit margin $\left(a-c^{u}\right)$ are sufficiently small, the increase in the affiliate's downstream profit that sabotage engenders will outweigh any countervailing decrease in upstream profit. However, since sabotage can reduce the rival's downstream output, it can thereby reduce the rival's demand for access. Consequently, if the upstream profit margin is sufficiently large, sabotage can reduce the upstream profit more than it increases the downstream profit of the integrated firm. If it does so, sabotage will not arise in equilibrium. ${ }^{18}$

Propositions 2.1 and 2.2 suggest that, at least under the identified conditions, demand-reducing sabotage acts very much like cost-increasing sabotage. Both increase the downstream profit but may decrease the upstream profit of the integrated firm. As the analysis in section 3 reveals, this conclusion is sensitive to the type of competition that prevails downstream.

3. Bertrand Competition.

Now consider a setting that is analogous to the setting analyzed in section 2 except that the downstream firms engage in Bertrand (price-setting) competition rather than Cournot (quantitysetting) competition. The notation employed to analyze this setting is identical to the notation

18. This conclusion reflects the insights of Weisman (1995) and Sibley and Weisman (1998, 1999), for example. 
developed above except that the demand curves facing the affiliate and the rival are denoted $Q^{d}\left(p^{d}, p^{r}\right)$ and $Q^{r}\left(p^{r}, p^{d}, s^{q}\right)$, respectively, where $p^{i}$ denotes the price set by downstream competitor $i \in\{d, r\}$.

The products sold by the two downstream competitors continue to be gross substitutes (so $Q_{2}^{i}(\cdot)>0$ for $\left.i=d, r\right)$ in this Bertrand setting. Furthermore, the maximum amount that each downstream firm can sell declines as its price increases (so $Q_{1}^{i}(\cdot)<0$ for $i=d, r$ ). In addition, demand-reducing sabotage continues to reduce demand for the rival's product (so $Q_{3}^{r}(\cdot)<0$ ).

In this Bertrand setting, for given prices and sabotage levels, the profit of the upstream and downstream divisions of the integrated firm and the rival are, respectively:

$$
\begin{aligned}
& \Pi^{u}\left(p^{d}, p^{r}, s^{c}, s^{q}\right)=\left[a-c^{u}\right]\left[Q^{d}\left(p^{d}, p^{r}\right)+Q^{r}\left(p^{r}, p^{d}, s^{q}\right)\right]-F^{u}-K\left(s^{c}, s^{q}\right) ; \\
& \Pi^{d}\left(p^{d}, p^{r}, s^{c}, s^{q}\right)=\left[p^{d}-c^{d}-a\right] Q^{d}\left(p^{d}, p^{r}\right)-F^{d} ; \text { and } \\
& \Pi^{r}\left(p^{r}, p^{d}, s^{c}, s^{q}\right)=\left[p^{r}-c^{r}-a-s^{c}\right] Q^{r}\left(p^{r}, p^{d}, s^{q}\right)-F^{r} .
\end{aligned}
$$

$\Pi^{I}(\cdot)=\Pi^{u}(\cdot)+\Pi^{d}(\cdot)$ again denotes the total profit of the integrated firm. ${ }^{19}$

We adopt the standard assumption that downstream prices are strategic complements (i.e., $\Pi_{12}^{i}(\cdot)>0$ for $\left.i=I, r\right) .{ }^{20}$ This assumption ensures that an increase in one firm's price increases

19. We assume the existence of prices $\left(\bar{p}^{d}, \bar{p}^{r}\right)$ above marginal costs such that $Q^{d}\left(\bar{p}^{d}, \bar{p}^{r}\right)=0$ and $Q^{r}\left(\bar{p}^{r}, \bar{p}^{d}, 0\right)=0$. This assumption ensures that the strategy spaces $p^{d} \in S^{d} \equiv\left[c^{d}+c^{u}, \bar{p}^{d}\right]$ and $p^{r} \in S^{r} \equiv\left[c^{r}+a, \bar{p}^{r}\right]$ are compact. Notice that all values of $p^{d}$ below marginal cost can be eliminated from $S^{d}$ without loss of generality because such values are not optimal. In contrast, although values of $p^{r}$ below the rival's marginal cost, $c^{r}+a+s^{c}$, are not optimal, $s^{c}$ generally cannot be included as part of the lower bound on $S^{r}$ when citing standard theorems about supermodular games. Such inclusion would render the strategy space dependent on the comparative static parameter $s^{c}$.

20. Since $\Pi_{12}^{I}=Q_{2}^{d}+\left[p^{d}-c^{d}-c^{u}\right] Q_{12}^{d}+\left[a-c^{u}\right] Q_{12}^{r}$, a sufficient condition for $\Pi_{12}^{I}>0$ for all $\left(p^{d}, p^{r}\right) \in S^{d} X S^{r}$ is that the inverse demand curve facing each downstream competitor becomes steeper as its opponent's price increases (i.e., $Q_{12}^{i} \geq 0$ for $i=d, r$ ). This condition is not sufficient to ensure $\Pi_{12}^{r}>0$ for all $\left(p^{d}, p^{r}\right) \in S^{d} X S^{r}$ because $p^{r}$ may be below $c^{r}+a+s^{c}$. $Q_{2}^{r}$ must exceed $\left[p^{r}-c^{r}-a-s^{c}\right] Q_{12}^{r}$ everywhere on $S^{d} X S^{r}$ to ensure that $\Pi_{12}^{r}>0$ globally. 
the marginal return to the other firm from an increase in its price. Consequently, the Bertrand subgame is supermodular. ${ }^{21}$ Therefore, if increases in sabotage systematically increase (respectively, reduce) both firms' incremental returns from raising their prices, higher levels of sabotage will increase (respectively, reduce) the equilibrium prices of both the affiliate and the rival (Vives, 1999, p. 35).

Higher levels of cost-increasing sabotage always increase the rival's incremental return from raising its price (i.e., $\left.\Pi_{13}^{r}\left(p^{r}, p^{d}, s^{c}, s^{q}\right)=-Q_{1}^{r}\left(p^{r}, p^{d}, s^{q}\right)>0\right)$. This is because, by raising its price, the rival reduces the number of units of output on which it incurs the higher marginal cost caused by the increased cost-increasing sabotage. Moreover, cost-increasing sabotage does not affect the affiliate's incremental return from raising its price (i.e., $\left.\Pi_{13}^{I}\left(p^{d}, p^{r}, s^{c}, s^{q}\right)=0\right)$. Therefore, as reported in Lemma 3.1 below, cost-increasing sabotage will never cause downstream prices to decline.

The effects of demand-reducing sabotage are more complicated under Bertrand competition, as they are under Cournot competition. Demand-reducing sabotage shifts the rival's inverse demand curve inward, which encourages the rival to reduce its price. However, two countervailing effects could arise. First, if demand-reducing sabotage were to reduce the sensitivity of the rival's demand to its price, the rival could increase its price without suffering as great a reduction in quantity demanded. Consequently, the rival might prefer to set a higher price. ${ }^{22}$ Second, if demand-reducing

21. See Vives (1999, p. 151) and the references cited in section 2.

22. This potential countervailing effect is analogous to the potential countervailing effect of demandreducing sabotage under Cournot competition, but it works in the opposite direction. Under both Cournot and Bertrand competition, the effect of demand-reducing sabotage will be unambiguous only if it affects the slope of the rival's inverse demand so as to reinforce the inward shift of the inverse demand. The reinforcement arises under Cournot competition when the inverse demand becomes steeper, which renders a quantity reduction more profitable for the rival. The reinforcement arises under Bertrand competition when the inverse demand curve becomes less steep, which renders a price decrease more profitable for the rival. 
sabotage were to render the rival's demand more responsive to increases in the affiliate's price, the affiliate might prefer to increase its price. The higher price could conceivably induce a sufficiently large increase in the rival's output, and thus its demand for access, as to increase upstream profit. ${ }^{23}$

Assumptions (A3.1) and (A3.2) are sufficient to preclude these two countervailing effects. Assumption (A3.1) ensures that demand-reducing sabotage makes the rival's demand more sensitive to increases in the rival's price. Assumption (A3.2) ensures that when upstream effects are relevant (in particular, when $a>c^{u}$ ), increases in demand-reducing sabotage render the rival's demand less sensitive to increases in the affiliate's price.

Assumption (A3.1). $\quad Q_{13}^{r}\left(p^{r}, p^{d}, s^{q}\right) \leq 0$.

Assumption (A3.2). $\quad\left[a-c^{u}\right] Q_{23}^{r}\left(p^{r}, p^{d}, s^{q}\right) \leq 0$.

Consequently, when assumptions (A3.1) and (A3.2) hold, higher levels of demand-reducing sabotage reduce the marginal profitability of price increases for both the rival and the affiliate (i.e., $\Pi_{14}^{r}(\cdot) \leq 0$ and $\left.\Pi_{14}^{I}(\cdot) \leq 0\right){ }^{24}$ Therefore, Lemma 3.1 follows. $^{25}$

Lemma 3.1. Under downstream Bertrand competition:

23. No analogue to this second potential countervailing effect arises under Cournot competition. This is because the Cournot affiliate conjectures that the rival's quantity is fixed (i.e., unresponsive to demandreducing sabotage), and it is the rival's quantity, not its price, that directly enters the affiliate's objective. The Cournot affiliate thus anticipates no effect on upstream profit from an increase in demand-reducing sabotage.

24. When analyzing changes in $s^{q}$ we can, without loss of generality, consider a modified version of the game in which the strategy space of the rival is $\tilde{S}^{r} \equiv\left[c^{r}+a+s^{c}, \bar{p}^{r}\right]$. In this modified game, $Q_{12}^{i} \geq 0$ for $i=r, d$ is sufficient for strategic complementarity, $Q_{13}^{r} \leq 0$ is sufficient for $\Pi_{14}^{r}<0$, and $\left[a-c^{u}\right] Q_{23}^{r} \leq 0$ is sufficient for $\Pi_{14}^{I} \leq 0$.

25. It follows from Vives (1999, pp. 33-34) that an equilibrium exists in the setting under consideration. If the equilibrium is not unique, the conclusions in Lemma 3.1 (and all ensuing formal conclusions) pertain to the extremal equilibria (Vives, 1999, pp. 34-45). 
(i) the equilibrium downstream prices of both the affiliate and the rival are non-decreasing in the level of cost-increasing sabotage; and

(ii) the equilibrium downstream prices of both the affiliate and the rival are non-increasing in the level of demand-reducing sabotage if assumptions (A3.1) and (A3.2) hold. More generally, the effects of increased demand-reducing sabotage on downstream prices are ambiguous. $^{26}$

Since cost-increasing sabotage induces the rival to raise its price, the resulting increase in demand for the affiliate's product ensures higher downstream profit for the integrated firm. Therefore, absent upstream effects, cost-increasing sabotage always increases the profit of the integrated firm. This conclusion is recorded formally as Proposition 3.1.

Proposition 3.1. When upstream effects are absent and the downstream firms engage in Bertrand competition, the upstream producer will undertake cost-increasing sabotage.

Demand-reducing sabotage can affect the profit of the integrated firm differently than does costincreasing sabotage under Bertrand competition. When assumption (A3.1) holds, demand-reducing sabotage induces the rival to lower the price it charges for its product. The reduced price for the rival's product reduces the demand for the affiliate's product, which reduces the downstream profit of the integrated firm. Therefore, absent upstream effects, demand-reducing sabotage would reduce the profit of the integrated firm in the Bertrand setting, and so would not be undertaken, as Proposition 3.2 reports.

26. It can be shown that the equilibrium in the Bertrand subgame is unique under the maintained assumptions if, in addition, assumption (A3.4) (stated below) holds. When the Bertrand equilibrium is unique and interior: (i) the equilibrium prices of both the affiliate and the rival strictly increase as costincreasing sabotage increases; and (ii) the equilibrium prices of both the affiliate and the rival strictly decrease as demand-reducing sabotage increases if assumptions (A3.1) and (A3.2) hold. These conclusions can be proved using conventional comparative static analysis (Mandy and Sappington, 2001). 
Proposition 3.2. When upstream effects are absent, assumption (A3.1) holds, and the downstream

firms engage in Bertrand competition, the upstream producer will not undertake demandreducing sabotage.

The upstream effects of sabotage remain to be considered. The upstream effects of costincreasing sabotage can introduce a countervailing effect on the integrated firm's profit under Bertrand competition, as they do under Cournot competition. The price increases that cost-increasing sabotage induce can reduce the rival's downstream output, and thus the rival's demand for access. Consequently, if the direct costs of initial increments in sabotage $\left(K_{1}\left(0, s^{q}\right)\right.$ and $\left.K_{2}\left(s^{c}, 0\right)\right)$ and the upstream profit margin $\left(a-c^{u}\right)$ are sufficiently large, the upstream losses from cost-increasing sabotage can outweigh the downstream gains. When this is the case, no cost-increasing sabotage will arise in equilibrium.

Upstream considerations can introduce additional effects of demand-reducing sabotage on equilibrium profits. The direct upstream effects of demand-reducing sabotage reduce the profit of the integrated firm by introducing sabotage costs $(K(\cdot))$ and reducing the rival's demand for access. Therefore, these direct effects reinforce the downstream effects that underlie Proposition 3.2. However, the indirect upstream effect of demand-reducing sabotage is a countervailing one. The equilibrium price reductions induced by demand-reducing sabotage stimulate increased rival demand for access, and thereby increase upstream profit. Assumptions (A3.3) and (A3.4) ensure that this countervailing indirect upstream effect of demand-reducing sabotage under Bertrand competition does not dominate the corresponding downstream and direct upstream effects.

Assumption (A3.3). $\quad Q_{13}^{r}\left(p^{r}, p^{d}, s^{q}\right)=Q_{23}^{r}\left(p^{r}, p^{d}, s^{q}\right)=0$.

Assumption (A3.4). (i) $\left|Q_{1}^{i}(\cdot)\right| \geq Q_{2}^{i}(\cdot)$ for $i=d$, $r$; (ii) $Q_{11}^{i}(\cdot)+Q_{12}^{i}(\cdot) \leq 0$ for $i=d, r$; and (iii) $Q_{22}^{r}(\cdot)+Q_{21}^{r}(\cdot) \leq 0$. 
Assumption (A3.3) ensures that demand-reducing sabotage shifts the rival's demand curve inward without changing its slope and without changing its sensitivity to the affiliate's price. When assumption (A3.3) holds, the reduction in the rival's price caused by demand-reducing sabotage will be relatively limited. Condition (i) of assumption (A3.4) is the standard assumption that each firm's demand varies more with changes in its own price than with changes in its opponent's price. Condition (ii) states that equal reductions in both downstream prices $\left(p^{d}\right.$ and $\left.p^{r}\right)$ render each competitor's demand less sensitive to its own price, and thereby reduce the appeal of further price reductions. Condition (iii) states that equal reductions in both downstream prices render the rival's demand more sensitive to changes in the affiliate's price. ${ }^{27}$ This increased sensitivity increases the rate at which upstream profit declines due to reduced demand for access by the rival as the affiliate's downstream price $\left(p^{d}\right)$ declines.

Together, assumptions (A3.3) and (A3.4) ensure that initial price reductions both reduce the potential downstream gains from further price reductions for the affiliate and the rival and render further price reductions by the affiliate more costly in terms of reduced access demand by the rival. Consequently, the downstream and direct upstream effects of demand-reducing sabotage outweigh its indirect upstream effect (i.e., increased rival demand for access due to induced price reductions) under these conditions, and so sabotage will not be profitable for the integrated firm. This conclusion is stated formally in Proposition 3.3. ${ }^{28}$

27. Notice that conditions (ii) and (iii) of assumption (A3.4) hold, for example, when demand curves are additively separable and concave in prices (i.e., when $Q_{12}^{i}(\cdot)=0$ and $Q_{j j}^{i}(\cdot) \leq 0$ for $i=d, r$ and for $j=1,2)$.

28. As indicated in footnote 26 and demonstrated in the proof of Proposition 3.3, assumption (A3.4) ensures the Bertrand equilibrium is unique and stable. A relatively strong assumption like assumption (A3.4) is required to ensure that demand-reducing sabotage will not arise in equilibrium even though the Bertrand subgame is supermodular and has monotone marginal payoffs under assumptions (A3.1) and (A3.2). This is because supermodularity and monotonicity of marginal payoffs do not guarantee monotonicity of equilibrium payoffs in the presence of potentially countervailing upstream effects. 
Proposition 3.3. When assumptions (A3.3) and (A3.4) hold and the downstream firms engage in

Bertrand competition, the upstream firm will not undertake demand-reducing sabotage. ${ }^{29}$

In summary, Propositions $2.1-3.3$ reveal that the incentives for sabotage vary according to both

the type of sabotage and the nature of downstream competition. Cost-increasing sabotage tends to raise the downstream profit of the integrated producer under both Cournot and Bertrand competition, but may reduce upstream profit. Demand-reducing sabotage has similar effects under Cournot competition. However, demand-reducing sabotage tends to reduce downstream profit under Bertrand competition, and so may not arise in equilibrium. ${ }^{30}$

\section{The Effects of Product Differentiation.}

Sabotage can benefit the integrated producer by enabling the affiliate to capture some of the customer demand that would otherwise accrue to the rival. The increase in demand for the affiliate's product that arises as the rival's equilibrium output declines in response to sabotage generally will vary with the degree of product differentiation in the industry. Economides (1998) and Mandy (2000) demonstrate that strong incentives for sabotage can arise when the affiliate and rival produce homogeneous products. The purpose of this section is to examine how incentives for sabotage vary

29. Under the conditions of Proposition 3.3, demand-reducing sabotage causes a strict decline in the profit of the integrated supplier, even if the sabotage is costless. Therefore, the integrated supplier would refrain from demand-reducing sabotage even if (as Reiffen (1998) suggests) the supplier experienced some cost savings by doing so, provided the cost savings were not too pronounced. Furthermore, since demand-reducing sabotage reduces the integrated supplier's profit, the supplier might benefit by undertaking actions that increase (rather than decrease) the demand for the rival's product.

30. Demand-reducing sabotage can strictly reduce the profit of the integrated firm. Consequently, if costincreasing and demand-reducing sabotage are inextricably linked, the losses from demand-reducing sabotage may outweigh the gains from cost-increasing sabotage, and so the integrated producer may refrain from both types of sabotage. The two types of sabotage may be inextricably linked, for example, when providing inferior quality access both imposes costs on a rival and reduces customer perception of the rival's reliability. We thank Dennis Weisman for pointing out this possibility. 
with the degree of product differentiation. ${ }^{31}$

To provide a convenient parameterization of product heterogeneity, we follow Vives (1984; 1999 , p. 145) and assume there is a representative consumer with the following quadratic utility function for the outputs of the affiliate $\left(q^{d}\right)$ and the rival $\left(q^{r}\right)$ :

$$
\left.U\left(q^{d}, q^{r}\right)=\alpha^{d} q^{d}+\alpha^{r} q^{r}-\frac{1}{2}\left[\beta\left(q^{d}\right)^{2}+2 \gamma q^{d} q^{r}+\beta\left(q^{r}\right)^{2}\right] \text { for } \gamma \in[0, \beta\}^{4.1}\right)
$$

This utility function gives rise to the following linear inverse demand functions:

$$
P^{i}\left(q^{i}, q^{j}\right)=\alpha^{i}-\beta q^{i}-\gamma q^{j} \quad \text { for } j \neq i, \quad i, j=d, r
$$

The parameter $\gamma \in[0, \beta]$ reflects the degree of product homogeneity in this setting. When $\gamma$ $=0$, the products of the affiliate and the rival are fully differentiated in the sense that the demand for each firm's product is not affected by the competitor's price or output level. When $\gamma=\beta$, the products of the affiliate and rival are homogeneous, because each firm's demand declines as its own price rises at the same rate that its demand increases as the price of its competitor rises.

Absent demand-reducing sabotage, the affiliate and rival are assumed to face symmetric demands, so $\alpha^{d}=\alpha^{r}=\alpha>0$. Each unit of demand-reducing sabotage $\left(s^{q}\right)$ reduces the intercept of the rival's inverse demand curve by one unit (so $\alpha^{r}=\alpha-s^{q} \leq \alpha=\alpha^{d}$ ). Each unit of cost-increasing sabotage $\left(s^{c}\right)$ increases the rival's marginal cost by one unit. For simplicity, we abstract from fixed costs of production (so $F^{u}=F^{d}=F^{r}=0$ ) and from direct costs of sabotage (so $K\left(s^{c}, s^{q}\right)=0$ for all $\left.s^{c}, s^{q}\right)$.

It is apparent that assumptions (A3.3) and (A3.4) are satisfied in this setting, which we call the linear setting. ${ }^{32}$ Consequently, from Proposition 3.3, the integrated producer will never undertake

31. Kang and Weisman (2001) examine how incentives for cost-increasing sabotage vary with the crossprice elasticity of demand under Bertrand competition.

32. Demand-reducing sabotage must be parameterized differently in the linear setting under downstream Bertrand competition. When $\alpha^{d}=\alpha$ and $\alpha^{r}=\alpha-s^{q}$, the intercepts of both the rival's and the affiliate's demand curve decline as $s^{q}$ increases, even though only the intercept of the rival's inverse 
demand-reducing sabotage when the affiliate and rival engage in Bertrand competition. Hence, we focus our analysis of the linear setting on the case where the affiliate and rival engage in Cournot competition. However, as we emphasize when concluding this section, most of the key qualitative conclusions regarding sabotage under Cournot competition persist with regard to cost-increasing sabotage under Bertrand competition. ${ }^{33}$

It is readily verified that the Cournot equilibrium in the linear setting is unique (Vives, 1999, p. 158) and stable. It is also readily shown that when they are non-negative, equilibrium output levels in the linear setting under Cournot competition are:

$$
\begin{aligned}
& q^{r *}=\left\{2 \beta\left[\alpha-s^{q}-a-c^{r}-s^{c}\right]-\gamma\left[\alpha-c^{u}-c^{d}\right]\right\} / J, \text { and } \\
& q^{d *}=\left\{2 \beta\left[\alpha-c^{u}-c^{d}\right]-\gamma\left[\alpha-s^{q}-a-c^{r}-s^{c}\right]\right\} / J,
\end{aligned}
$$

where $J=4 \beta^{2}-\gamma^{2}>0$. We focus on the setting of greatest interest where, in the absence of sabotage, the affiliate and rival both supply strictly positive levels of output in equilibrium. From (4.3) and (4.4), this will be the case for all $\gamma \in[0, \beta]$ when the firms engage in Cournot competition if:

$$
0<\frac{1}{2}\left[\alpha-c^{u}-c^{d}\right] \leq \alpha-a-c^{r} \leq 2\left[\alpha-c^{u}-c^{d}\right] .
$$

Inequality (4.5) simply rules out settings in which the operating costs of the affiliate and the rival are very different.

Notice from (4.3) and (4.4) that cost-increasing and demand-reducing sabotage affect equilibrium outputs symmetrically. Furthermore, since the equilibrium profit of the integrated firm is:

demand curve declines as $s^{q}$ increases. A parameterization in which only the intercept of the rival's demand curve declines as $s^{q}$ increases is $\alpha^{d}=\alpha-\gamma s^{q}$ and $\alpha^{r}=\alpha-\beta s^{q}$. Assumptions (A3.3) and (A3.4) hold under this parameterization.

33. The proofs of our findings regarding the linear setting with Bertrand competition are fairly lengthy and tedious, and so are omitted. 


$$
\pi^{I *}=\left[a-c^{u}\right] q^{r *}+\left[P^{d}\left(q^{d *}, q^{r *}\right)-c^{u}-c^{d}\right] q^{d *}
$$

it is readily verified that this profit can be written exclusively as a function of aggregate sabotage, $s \equiv s^{c}+s^{q}$. (Here and throughout, we denote the equilibrium value of a variable with a “*”.) Observation 4.1 describes an important property of this function, $\pi^{I *}(s)$.

Observation 4.1. The integrated firm's profit is a strictly convex function of sabotage in the linear setting with Cournot competition (i.e., $\pi^{I *^{\prime \prime}}(s)>0$ for all $\left.s>0\right)$ for all $\gamma \in(0, \beta] .^{34}$

The convexity identified in Observation 4.1 arises for the following reason. When a monopolist operates with constant marginal cost, its profit increases at an increasing rate as the intercept of the linear inverse demand curve that it faces increases. This convexity and the fact that sabotage increases the intercept of the affiliate's equilibrium inverse residual demand curve at a constant rate in the linear setting together yield Observation 4.1. Because the integrated firm's profit is convex in sabotage, the firm will either refrain from sabotage or undertake the foreclosure level of sabotage, $\bar{s}$, which is the level of sabotage that drives the rival's equilibrium output to zero.

As noted above, Economides (1998) and Mandy (2000) have shown that the integrated firm will undertake the foreclosure level of sabotage in the linear setting when products are homogeneous and the affiliate's operating cost does not exceed the rival's operating cost. When products are homogeneous, the affiliate is best able to capture rival demand that is displaced by sabotage. Consequently, as long as the affiliate is at least as efficient as the rival in serving customers, the integrated firm will effectively transfer all of the rival's demand to the affiliate by undertaking the foreclosure level of sabotage. For completeness, this finding is recorded as Observation 4.2.

Observation 4.2. (Economides, 1998; Mandy, 2000). Suppose the affiliate's downstream cost is no larger than the rival's downstream cost (so $c^{d} \leq c^{r}$ ). Then the integrated producer will

34. The integrated firm's profit is linear in sabotage (i.e., $\pi^{I *^{\prime \prime}}(s)=0$ ) if $\gamma=0$. 
undertake the foreclosure level of sabotage when products are homogeneous in the linear setting with Cournot competition (i.e., $s^{*}=\bar{s}$ when $\gamma=\beta$ ).

In contrast, the integrated firm will have no incentive to reduce the rival's output when products are fully differentiated (i.e., when $\gamma=0$ ). In this case, reduced rival output does not increase demand for the affiliate's product. Consequently, sabotage only serves to reduce upstream demand for the input, and thereby reduces the profit of the integrated firm whenever its upstream margin $\left(a-c^{u}\right)$ is positive. This conclusion is stated as Observation 4.3.

Observation 4.3. Suppose that sales of the input are profitable (so $a>c^{u}$ ). Then the integrated producer will refrain from sabotage when products are fully differentiated in the linear setting with Cournot competition (i.e., $s^{*}=0$ when $\gamma=0$ ).

Observations 4.2 and 4.3 reveal that the incentive for sabotage is generally absent when products are fully differentiated, but can be particularly strong when products are homogeneous. It remains to determine whether the incentive for sabotage increases systematically as products become more homogeneous (i.e., as $\gamma$ increases toward $\beta$ ). Observation 4.4 reports that this is the case when the affiliate is at least as efficient as the rival. ${ }^{35}$

Observation 4.4. Suppose the upstream profit margin is strictly positive and the affiliate's downstream cost is no larger than the rival's downstream cost. Then the integrated producer will refrain from sabotage when products are sufficiently differentiated and undertake the foreclosure level of sabotage when products are sufficiently homogeneous in the linear setting with Cournot competition. (Formally, if $c^{u}<a$ and $c^{d} \leq c^{r}$, then there exists $\tilde{\gamma} \in(0, \beta)$

35. A weaker sufficient condition is $\alpha-a-c^{r} \leq 5\left[\alpha-c^{d}-c^{u}\right] / 4$. 
such that $s^{*}=0$ if $\gamma \in[0, \tilde{\gamma}]$ and $s^{*}=\bar{s}$ if $\left.\gamma \in(\tilde{\gamma}, \beta].\right)^{36}$

In contrast, when the rival has lower operating costs than the affiliate, incentives for sabotage do not necessarily increase monotonically with the degree of product homogeneity, as Observation 4.5 reports.

Observation 4.5. Suppose the upstream margin for the integrated firm is relatively large (i.e., $\left.a-c^{u}>\left[\alpha-c^{d}-c^{u}\right] / 4\right)$ and the rival's operating cost is small relative to the affiliate's operating cost (i.e., $\alpha-a-c^{r}>5\left[\alpha-c^{d}-c^{u}\right] / 4$ ). Then the integrated firm may undertake more sabotage as products become less homogeneous (i.e., $s^{*}$ may increase from 0 to $\bar{s}$ as $\gamma$ declines over some ranges).

The non-monotonic relationship between sabotage and product homogeneity identified in Observation 4.5 can arise because of the following two considerations. First, recall that when the rival has lower operating costs than the affiliate, the integrated firm may prefer to refrain from sabotage even when products are homogeneous (Mandy, 2000). Although sabotage would secure greater downstream profit for the affiliate, it would sacrifice too much upstream profit by reducing the rival's relatively large demand for the input. Thus, when the upstream margin is of intermediate magnitude, the integrated firm can have a slight preference to refrain from sabotage when products are homogeneous.

Second, the rival's output can fall as the products become less homogeneous. It will do so if the increase in the affiliate's output caused by increased product differentiation is large enough to shift the rival's equilibrium inverse residual demand curve to the left.

Now consider an integrated firm that has an upstream margin of intermediate magnitude (and

36. If $a=c^{u}$, the integrated firm is indifferent among all levels of sabotage when $\gamma=0$, and strictly prefers the foreclosure level of sabotage to any smaller level when $\gamma>0$. This is the case because sabotage increases downstream profit when $\gamma>0$ and does not reduce upstream profit when $a=c^{u}$ (see equations (A4.14) and (A4.19) in the Appendix). 
so has a slight preference to refrain from sabotage when products are homogeneous) and that faces a rival whose residual inverse demand decreases as products become slightly differentiated. A small increase in product differentiation causes upstream profit to decrease (because the rival's demand for the input declines) and downstream profit to increase (because the affiliate's output rises). The reduction in input demand reduces upstream profit considerably when the upstream margin is of intermediate magnitude. In contrast, the increased output of the affiliate does not increase downstream profit substantially when the affiliate's downstream margin is relatively small. Thus, the net effect of an increase in product differentiation is to reduce the profit of the integrated firm. Because the integrated firm has only a mild preference to refrain from sabotage when products are homogeneous, the integrated firm can switch to preferring sabotage as products become slightly differentiated.

A corresponding non-monotonicity of cost-increasing sabotage does not arise in the linear setting with downstream Bertrand competition. ${ }^{37}$ However, the qualitative conclusions reported in Observations 4.1 - 4.4 hold in this setting. In particular, the integrated firm will either refrain from sabotage or undertake the foreclosure level of cost-increasing sabotage..$^{38}$ It will refrain from costincreasing sabotage if products are sufficiently differentiated (i.e., if $\gamma \leq \hat{\gamma} \in(0, \beta])$ and the upstream profit margin is positive (i.e., $a>c^{u}$ ). The integrated firm will undertake the foreclosure level of cost-increasing sabotage when products are sufficiently homogeneous (i.e., when $\gamma>\hat{\gamma}$ ), the upstream margin is positive ( $a>c^{u}$ ), and the affiliate's operating costs are no higher than the rival's (so $c^{d} \leq c^{r}$ ).

37. Indeed, it can be shown that when the affiliate and rival always produce absent sabotage, the amount of cost-increasing sabotage that the integrated producer undertakes is non-decreasing in the degree of product homogeneity in the linear setting with Bertrand competition.

38. The foreclosure level of cost-increasing sabotage under Bertrand competition is the level that inflates the rival's marginal cost to the point where any price for the rival's product that exceeds this marginal cost places no effective constraints on the affiliate. 


\section{Summary and Conclusions.}

The existing literature offers two important insights regarding the incentives that a vertically integrated supplier may have to sabotage its downstream rivals. First, cost-increasing sabotage generally confers an advantage upon the affiliated downstream producer, and thereby increases its profit. Second, by reducing downstream output, sabotage can reduce demand for the upstream product, thereby reducing upstream profit. Thus, the literature suggests that the downstream benefits of cost-increasing sabotage must be weighed against the corresponding upstream costs to determine whether sabotage will occur in practice.

The present research has confirmed these two observations about cost-increasing sabotage in a variety of settings. It has also demonstrated that the gains from cost-increasing sabotage can be particularly pronounced when competitors' products are homogeneous, although greater product homogeneity need not increase incentives for sabotage systematically. In addition, this research has provided two observations about demand-reducing sabotage. First, the basic tradeoff between downstream gains and upstream losses under cost-increasing sabotage generally persist under demand-reducing sabotage in the presence of Cournot competition downstream. Second, and perhaps more importantly, demand-reducing sabotage may introduce no such tradeoff in the presence of Bertrand competition downstream. Under Bertrand competition, demand-reducing sabotage can reduce the downstream profit of the integrated supplier (by inducing rivals to react aggressively by setting lower prices for their products, which reduces the demand for the integrated firm's downstream product). Furthermore, there may be no countervailing upstream gains (since the sabotage can reduce downstream output, and thus demand for the upstream product). Therefore, in the presence of Bertrand competition downstream, an integrated supplier may have no incentive to engage in demand-reducing sabotage.

This finding does not suggest that the possibility of sabotage by a vertically integrated producer should be ignored when designing public policy toward vertical integration. It suggests instead that 
in order to fully assess the likelihood and extent of sabotage, one should consider carefully both the types of sabotage that might be undertaken and the nature of the relevant downstream competition. The findings also provide some guidance regarding the types of sabotage that merit the closest scrutiny if monitoring of sabotage is undertaken to limit its incidence.

Although we have extended the literature by examining both demand-reducing and costincreasing sabotage, further extensions remain to be pursued. One extension is to analyze other types of sabotage. For instance, as Economides (1998) suggests, some forms of sabotage might unavoidably affect the downstream operations of the integrated producer as well as the operations of rivals. ${ }^{39}$ It is also possible that sabotage might serve primarily to raise a rival's cost of improving its service quality, rather than raising its marginal cost of production or directly reducing the demand for its product. Another extension that merits investigation is strategic pricing in conjunction with sabotage. It is apparent that an integrated supplier might undertake price discrimination to disadvantage downstream rivals (e.g., the supplier might charge rivals more for access than it charges its downstream affiliate). The supplier might also fail to implement legitimate cost-based price discrimination that would benefit rivals (Bernheim and Willig, 1996, p. 4.17). It would be useful to determine the extent to which strategic pricing and (non-price) sabotage are complementary or substitute activities.

The optimal design of regulatory policy in vertically-related industries also merits careful study. Our findings, along with others in the literature, suggest that there are conditions under which a regulator can mitigate incentives for sabotage by raising the price of the upstream product above its marginal cost of production. ${ }^{40}$ Doing so increases the integrated firm's opportunity cost of engaging

39. See Weisman (1998) for additional thoughts on this issue.

40. Regulators can also reduce incentives for sabotage by increasing the costs that an integrated producer incurs when it engages in sabotage. Regulators can devote more resources to monitoring sabotage and impose larger penalties if sabotage is detected, for example (Kang and Weisman, 2001). 
in sabotage that reduces the demand for the firm's upstream product. Thus, the standard prescription of marginal cost pricing for access may warrant reconsideration when the potential for sabotage is pronounced. $^{41}$

Incentives for sabotage may also be affected by the legal relationship between the upstream and the downstream units of the integrated firm. If the downstream firm is required to operate as a separate subsidiary, it may value the upstream profit generated by its purchases of the upstream product less highly than it otherwise would. Consequently, the downstream firm may increase the price it charges or reduce its output, thereby altering the nature of downstream competition. ${ }^{42}$ All of the ramifications of a separate subsidiary requirement merit investigation in a complete model of optimal regulatory policy in industries with vertically integrated production. Such a model should also allow the regulator to expend resources in an attempt to detect, and thereby deter, sabotage. ${ }^{43}$

It would be particularly useful to examine the design of regulatory policy in a setting where the regulator's knowledge of the industry is incomplete. In practice, an upstream producer often has privileged knowledge about its likely downstream operating costs and about its incentive and ability to sabotage the activities of its downstream rivals. The optimal manner in which to elicit this privileged information while limiting sabotage and increasing industry welfare is an important issue

41. Laffont and Tirole (2000, pp. 161-166) also note that pricing access at marginal cost may create incentives for exclusion. By adopting the proposal of the Coalition for Affordable Local and Long Distance Service on May 31, 2000, the Federal Communications Commission (FCC) has decided to move access charges rapidly toward the marginal cost of supplying access in the telecommunications industry (FCC, 2000).

42. Hinton et al. (1988) and Mandy (2000) discuss some related effects.

43. As Beard et al. (2001) suggest, the likely benefits and costs of fostering competition among upstream suppliers also merits careful consideration in any complete analysis of regulatory policy in verticallyrelated industries. 
for future research. ${ }^{44}$

44. Vickers (1995) and Lee and Hamilton (1999) examine the optimal design of industry structure in a setting with asymmetric information, but do not consider the possibility of sabotage. 


\section{APPENDIX}

\section{Proof of Proposition 2.1.}

Let $\left(q^{d *}\left(s^{c}, s^{q}\right), q^{r *}\left(s^{c}, s^{q}\right)\right)$ denote either of the extremal equilibria in the Cournot subgame. Also define $\pi^{I *}\left(s^{c}, s^{q}\right) \equiv \pi^{I}\left(q^{d *}\left(s^{c}, s^{q}\right), q^{r *}\left(s^{c}, s^{q}\right), s^{c}, s^{q}\right)$. For any $s^{c}>0$ :

$$
\begin{aligned}
& \pi^{* I}\left(s^{c}, s^{q}\right)-\pi^{* I}\left(0, s^{q}\right)= \\
& \pi^{I}\left(q^{d *}\left(s^{c}, s^{q}\right), q^{r *}\left(s^{c}, s^{q}\right), s^{c}, s^{q}\right)-\pi^{I}\left(q^{d *}\left(0, s^{q}\right), q^{r *}\left(0, s^{q}\right), 0, s^{q}\right) \\
& \geq \pi^{I}\left(q^{d *}\left(0, s^{q}\right), q^{r *}\left(s^{c}, s^{q}\right), s^{c}, s^{q}\right)-\pi^{I}\left(q^{d *}\left(0, s^{q}\right), q^{r *}\left(0, s^{q}\right), 0, s^{q}\right) .
\end{aligned}
$$

The inequality in (A2.1) holds because $q^{d *}\left(s^{c}, s^{q}\right)$ ensures the highest value for $\pi^{I}(\cdot)$, given $s^{c}, s^{q}$, and $q^{r *}\left(s^{c}, s^{q}\right)$.

When upstream effects are absent, (2.1) and (2.2) imply:

$$
\pi^{I}\left(q^{d}, q^{r}, s^{c}, s^{q}\right)=\left[P^{d}\left(q^{d}, q^{r}\right)-c^{d}-c^{u}\right] q^{d}-F^{d}-F^{u} .
$$

Substituting (A2.2) into (A2.1) provides:

$$
\begin{aligned}
\pi^{* I}\left(s^{c}, s^{q}\right) \geq \pi^{* I}\left(0, s^{q}\right)+ \\
\quad\left[P^{d}\left(q^{d *}\left(0, s^{q}\right), q^{r *}\left(s^{c}, s^{q}\right)\right)-P^{d}\left(q^{d *}\left(0, s^{q}\right), q^{r *}\left(0, s^{q}\right)\right)\right] q^{d *}\left(0, s^{q}\right) .
\end{aligned}
$$

The term in square brackets in (A2.3) is non-negative because $q^{r *}$ is non-increasing in $s^{c}$ (by Lemma 2.1) and $P^{d}(\cdot)$ is non-increasing in $q^{r}$ (by assumption). Consequently, $\pi^{I *}\left(s^{c}, s^{q}\right) \geq$ $\pi^{I *}\left(0, s^{q}\right)$. This inequality will be strict if the downstream equilibrium is interior and unique, because $q^{r *}$ is strictly decreasing in $s^{c}$ in this case (by Lemma 2.1; see footnote 17). (

\section{Proof of Proposition 2.2.}

Let $s^{q}>0$. It follows from the logic developed in the proof of Proposition 2.1 that when upstream effects are absent:

$$
\pi^{I *}\left(s^{c}, s^{q}\right) \geq \pi^{I *}\left(s^{c}, 0\right)
$$




$$
+\left[P^{d}\left(q^{d *}\left(s^{c}, 0\right), q^{r *}\left(s^{c}, s^{q}\right)\right)-P^{d}\left(q^{d *}\left(s^{c}, 0\right), q^{r *}\left(s^{c}, 0\right)\right)\right] q^{d *}\left(s^{c}, 0\right) .
$$

The term in square brackets in (A2.4) is non-negative because $q^{r *}$ is non-increasing in $s^{q}$ (by Lemma 2.1, provided assumption (A2.1) holds) and $P^{d}(\cdot)$ is non-increasing in $q^{r *}$ (by assumption). Consequently, $\pi^{I *}\left(s^{c}, s^{q}\right) \geq \pi^{I *}\left(s^{c}, 0\right)$. This inequality will hold strictly if the downstream equilibrium is interior and unique, because $q^{r *}$ is strictly decreasing in $s^{q}$ in this case (by Lemma 2.1; see footnote 17). (

\section{Proof of Propositions 3.1 and 3.2.}

Let $\left(p^{d *}\left(s^{c}, s^{q}\right), p^{r *}\left(s^{c}, s^{q}\right)\right)$ denote either of the extremal equilibria. Define

$$
\Pi^{I *}\left(s^{c}, s^{q}\right) \equiv \Pi^{I}\left(p^{d *}\left(s^{c}, s^{q}\right), p^{r *}\left(s^{c}, s^{q}\right), s^{c}, s^{q}\right),
$$

and consider any $s^{c}>0$. Since $p^{d *}\left(s^{c}, s^{q}\right)$ ensures the highest value for $\Pi^{I}(\cdot)$, given $s^{c}, s^{q}$, and $p^{r *}\left(s^{c}, s^{q}\right)$, it follows that:

$$
\begin{gathered}
\Pi^{I *}\left(s^{c}, s^{q}\right) \geq \Pi^{I *}\left(0, s^{q}\right)+\left[\Pi^{I}\left(p^{d *}\left(0, s^{q}\right), p^{r *}\left(s^{c}, s^{q}\right), s^{c}, s^{q}\right)\right. \\
\left.-\Pi^{I}\left(p^{d *}\left(0, s^{q}\right), p^{r *}\left(0, s^{q}\right), 0, s^{q}\right)\right] .
\end{gathered}
$$

From (3.1) and (3.2),

$$
\begin{aligned}
\Pi^{I}\left(p^{d}, p^{r}, s^{c}, s^{q}\right) & =\left[p^{d}-c^{d}-c^{u}\right] Q^{d}\left(p^{d}, p^{r}\right)-F^{d}-F^{u} \\
& +\left[a-c^{u}\right] Q^{r}\left(p^{r}, p^{d}, s^{q}\right)-K\left(s^{c}, s^{q}\right) .
\end{aligned}
$$

(A3.2) and (A3.3) imply that when upstream effects are absent (i.e., $a=c^{u}$ and $K(\cdot)=0$ ),

$$
\begin{aligned}
\Pi^{I *}\left(s^{c}, s^{q}\right) \geq \Pi^{I *}\left(0, s^{q}\right)+ & {\left[p^{d *}\left(0, s^{q}\right)-c^{d}-c^{u}\right]\left\lfloor Q^{d}\left(p^{d *}\left(0, s^{q}\right), p^{r *}\left(s^{c}, s^{q}\right)\right)\right.} \\
& \left.-Q^{d}\left(p^{d *}\left(0, s^{q}\right), p^{r *}\left(0, s^{q}\right)\right)\right\rfloor .
\end{aligned}
$$

The first term in square brackets in (A3.4), the profit margin, is non-negative in equilibrium because the affiliate can always set $p^{d}$ so high as to ensure shutdown. The second term in square brackets in (A3.4) is non-negative because $p^{r *}$ is non-decreasing in $s^{c}$ by Lemma 3.1 and $Q^{d}(\cdot)$ is non- 
decreasing in $p^{r}$ by assumption. Hence, $\Pi^{I *}\left(s^{c}, s^{q}\right) \geq \Pi^{I *}\left(0, s^{q}\right)$. That is, a positive level of cost-increasing sabotage is at least as profitable for the integrated firm as is no cost-increasing sabotage. If the downstream equilibrium is interior and unique, the inequality in (A3.4) is strict because: (i) the profit margin is strictly positive (otherwise, firm I's first order condition cannot hold); and (ii) $p^{r *}$ is strictly increasing in $s^{c}$, by Lemma 3.1 (see footnote 26). Therefore, the integrated firm will choose a strictly positive level of cost-increasing sabotage when the equilibrium is locally interior and unique at $s^{c}=0$ (absent upstream effects). This proves Proposition 3.1.

Now consider any $s^{q}>0$. The optimality of $p^{d *}\left(s^{c}, 0\right)$, given $s^{c}, 0$, and $p^{r *}\left(s^{c}, 0\right)$, implies:

$$
\begin{gathered}
\Pi^{I *}\left(s^{c}, s^{q}\right) \leq \Pi^{I *}\left(s^{c}, 0\right)+\left[\Pi^{I}\left(p^{d *}\left(s^{c}, s^{q}\right), p^{r *}\left(s^{c}, s^{q}\right), s^{c}, s^{q}\right)\right. \\
\left.-\Pi^{I}\left(p^{d *}\left(s^{c}, s^{q}\right), p^{r *}\left(s^{c}, 0\right), s^{c}, 0\right)\right] .
\end{gathered}
$$

Substituting from (A3.3) into (A3.5) provides:

$$
\begin{aligned}
& \Pi^{I *}\left(s^{c}, s^{q}\right) \leq \Pi^{I *}\left(s^{c}, 0\right) \\
& \quad+\left[p^{d *}\left(s^{c}, s^{q}\right)-c^{d}-c^{u}\right]\left[Q^{d}\left(p^{d *}\left(s^{c}, s^{q}\right), p^{r *}\left(s^{c}, s^{q}\right)\right)-Q^{d}\left(p^{d *}\left(s^{c}, s^{q}\right), p^{r *}\left(s^{c}, 0\right)\right)\right] \\
& \quad+\left[a-c^{u}\right]\left\lfloor Q^{r}\left(p^{r *}\left(s^{c}, s^{q}\right), p^{d *}\left(s^{c}, s^{q}\right), s^{q}\right)-Q^{r}\left(p^{r *}\left(s^{c}, 0\right), p^{d *}\left(s^{c}, s^{q}\right), 0\right)\right] \\
& \quad-\left\lfloor K\left(s^{c}, s^{q}\right)-K\left(s^{c}, 0\right)\right\rfloor .
\end{aligned}
$$

(A3.6) implies that when upstream effects are absent,

$$
\begin{aligned}
\Pi^{I *}\left(s^{c}, s^{q}\right) \leq \Pi^{I *}\left(s^{c}, 0\right) & +\left[p^{d *}\left(s^{c}, s^{q}\right)-c^{d}-c^{u}\right]\left[Q^{d}\left(p^{d *}\left(s^{c}, s^{q}\right), p^{r *}\left(s^{c}, s^{q}\right)\right)\right. \\
& \left.-Q^{d}\left(p^{d *}\left(s^{c}, s^{q}\right), p^{r *}\left(s^{c}, 0\right)\right)\right] .
\end{aligned}
$$

The second term in square brackets in (A3.7) is non-positive because $p^{r *}$ is non-increasing in $s^{q}$ by Lemma 3.1 (when assumption (A3.1) holds) and $Q^{d}(\cdot)$ is non-decreasing in $p^{r}$ by assumption. Hence, $\Pi^{I *}\left(s^{c}, s^{q}\right) \leq \Pi^{I *}\left(s^{c}, 0\right)$. That is, a positive level of demand-reducing sabotage is not strictly more profitable for the integrated firm than no sabotage. If the downstream equilibrium is 
interior and unique, then the inequality in (A3.7) is strict because $p^{r *}$ is strictly decreasing in $s^{q}$ by Lemma 3.1 (see footnote 26). So the integrated firm will choose zero demand-reducing sabotage when the equilibrium is locally interior and unique at $s^{q}=0$ (absent upstream effects, when assumption (A3.1) holds). This proves Proposition 3.2. (

\section{Proof of Proposition 3.3.}

From (A3.6), the conclusion in Proposition 3.2 continues to hold when $a>c^{u}$ and $K_{2}(\cdot)>0$ provided:

$$
Q^{r}\left(p^{r *}\left(s^{c}, s^{q}\right), p^{d *}\left(s^{c}, s^{q}\right), s^{q}\right)-Q^{r}\left(p^{r *}\left(s^{c}, 0\right), p^{d *}\left(s^{c}, s^{q}\right), 0\right) \leq 0 .
$$

For an infinitesimal change in $s^{q}$ at a unique interior equilibrium, inequality (A3.8) is:

$$
R \equiv Q_{3}^{r}\left(p^{r *}\left(s^{c}, s^{q}\right), p^{d *}\left(s^{c}, s^{q}\right), s^{q}\right)+Q_{1}^{r}(\cdot) \frac{\partial p^{r *}}{\partial s^{q}} \leq 0 .
$$

At a unique interior solution, the equilibrium prices $\left(p^{d *}, p^{r *}\right)$ are defined by:

$$
\Pi_{1}^{I}\left(p^{d *}, p^{r *}, s^{c}, s^{q}\right) \equiv 0 \text { and } \Pi_{1}^{r}\left(p^{r *}, p^{d *}, s^{c}, s^{q}\right) \equiv 0 .
$$

Differentiating (A3.10) with respect to $s^{q}$ and solving for the derivative of $p^{r *}$ with respect to $s^{q}$ yields:

$$
\frac{\partial p^{r *}}{\partial s^{q}}=\frac{\Pi_{14}^{I}(\cdot) \Pi_{12}^{r}(\cdot)-\Pi_{11}^{I}(\cdot) \Pi_{14}^{r}(\cdot)}{\Pi_{11}^{I}(\cdot) \Pi_{11}^{r}(\cdot)-\Pi_{12}^{I}(\cdot) \Pi_{12}^{r}(\cdot)} .
$$

It follows from (3.1) - (3.3) that, at the equilibrium:

$$
\begin{aligned}
& \Pi_{11}^{I}(\cdot)=2 Q_{1}^{d}(\cdot)+\left[p^{d *}-c^{d}-c^{u}\right] Q_{11}^{d}(\cdot)+\left[a-c^{u}\right] Q_{22}^{r}(\cdot), \\
& \Pi_{12}^{I}(\cdot)=Q_{2}^{d}(\cdot)+\left[p^{d *}-c^{d}-c^{u}\right] Q_{12}^{d}(\cdot)+\left[a-c^{u}\right] Q_{12}^{r}(\cdot), \\
& \Pi_{14}^{I}(\cdot)=\left[a-c^{u}\right] Q_{23}^{r}(\cdot), \\
& \Pi_{11}^{r}(\cdot)=2 Q_{1}^{r}(\cdot)+\left[p^{r *}-c^{r}-a-s^{c}\right] Q_{11}^{r}(\cdot), \\
& \Pi_{12}^{r}(\cdot)=Q_{2}^{r}(\cdot)+\left[p^{r *}-c^{r}-a-s^{c}\right] Q_{12}^{r}(\cdot), \text { and }
\end{aligned}
$$




$$
\Pi_{14}^{r}(\cdot)=Q_{3}^{r}(\cdot)+\left[p^{r *}-c^{r}-a-s^{c}\right] Q_{13}^{r}(\cdot) .
$$

Substituting equations (A3.12) - (A3.17) into (A3.11) and using assumption (A3.3) provides:

$$
\frac{\partial p^{r *}}{\partial s^{q}} \equiv \frac{-\Pi_{11}^{I}(\cdot) Q_{3}^{r}(\cdot)}{\Pi_{11}^{I}(\cdot) \Pi_{11}^{r}(\cdot)-\Pi_{12}^{I}(\cdot) \Pi_{12}^{r}(\cdot)} .
$$

It follows from (A3.12), (A3.13), (A3.15), and (A3.16) that:

$$
\begin{aligned}
& \Pi_{11}^{I}(\cdot)+\Pi_{12}^{I}(\cdot) \equiv Q_{1}^{d}(\cdot)+\left[Q_{1}^{d}(\cdot)+Q_{2}^{d}(\cdot)\right]+\left[p^{d *}-c^{d}-c^{u}\right]\left[Q_{11}^{d}(\cdot)+Q_{12}^{d}(\cdot)\right] \\
&+\left[a-c^{u}\right]\left[Q_{22}^{r}(\cdot)+Q_{21}^{r}(\cdot)\right]<0 ; \text { and } \\
& \Pi_{11}^{r}(\cdot)+\Pi_{12}^{r}(\cdot) \equiv Q_{1}^{r}(\cdot)+\left[Q_{1}^{r}(\cdot)+Q_{2}^{r}(\cdot)\right] \\
& \quad+\left[p^{r *}-c^{r}-a-s^{c}\right]\left[Q_{11}^{r}(\cdot)+Q_{12}^{r}(\cdot)\right]<0 \text {. }
\end{aligned}
$$

The inequalities in (A3.19) and (A3.20) follow from assumption (A3.4) and the fact that profit margins are positive at an interior equilibrium. Inequalities (A3.19) and (A3.20) and the assumption of strategic complementarity imply:

$$
-\Pi_{11}^{i}(\cdot)>\Pi_{12}^{i}(\cdot)>0 \text { for } i=I, r .
$$

(A3.21) implies that the denominator of expression (A3.18) is positive, indicating that assumption (A3.4) is sufficient for stability of the equilibrium.

Substituting equations (A3.12) - (A3.18) into (A3.9) provides:

$$
\begin{aligned}
& R=\frac{Q_{3}^{r}(\cdot)\left[\Pi_{11}^{I}(\cdot) \Pi_{11}^{r}(\cdot)-\Pi_{12}^{I}(\cdot) \Pi_{12}^{r}(\cdot)-Q_{1}^{r}(\cdot) \Pi_{11}^{I}(\cdot)\right]}{\Pi_{11}^{I}(\cdot) \Pi_{11}^{r}(\cdot)-\Pi_{12}^{I}(\cdot) \Pi_{12}^{r}(\cdot)} \\
& \stackrel{s}{=}-\left[\Pi_{11}^{I}(\cdot) \Pi_{11}^{r}(\cdot)-\Pi_{12}^{I}(\cdot) \Pi_{12}^{r}(\cdot)-Q_{1}^{r}(\cdot) \Pi_{11}^{I}(\cdot)\right] \\
& =-\Pi_{11}^{I}(\cdot)\left[Q_{1}^{r}(\cdot)+\left[p^{r *}-c^{r}-a-s^{c}\right] Q_{11}^{r}(\cdot)\right]+\Pi_{12}^{I}(\cdot) \Pi_{12}^{r}(\cdot) \\
& <-\Pi_{11}^{I}(\cdot)\left[Q_{1}^{r}(\cdot)+\left[p^{r *}-c^{r}-a-s^{c}\right] Q_{11}^{r}(\cdot)\right]-\Pi_{11}^{I}(\cdot) \Pi_{12}^{r}(\cdot)
\end{aligned}
$$




$$
\begin{aligned}
& \stackrel{s}{=} Q_{1}^{r}(\cdot)+\left[p^{r *}-c^{r}-a-s^{c}\right] Q_{11}^{r}(\cdot)+\Pi_{12}^{r}(\cdot) \\
& =\left[Q_{1}^{r}(\cdot)+Q_{2}^{r}(\cdot)\right]+\left[p^{r *}-c^{r}-a-s^{c}\right]\left[Q_{11}^{r}+Q_{12}^{r}\right] \leq 0 .
\end{aligned}
$$

(A3.23) holds because the denominator in (A3.22) is positive and $Q_{3}^{r}(\cdot)<0$. (A3.25) and (A3.26) follow from (A3.21). The inequality in (A3.27) follows from assumption (A3.4) and the fact that the rival's profit margin is positive at an interior equilibrium. (

\section{Proof of Observations 4.1 and 4.3.}

Substituting from (4.2) - (4.4) into (4.6) provides:

$$
\begin{gathered}
\pi^{I *}(s)=\frac{1}{J^{2}}\left\{\left[a-c^{u}\right] J\left[2 \beta\left[\alpha-a-c^{r}-s\right]-\gamma\left[\alpha-c^{u}-c^{d}\right]\right]\right. \\
\left.+\beta\left[2 \beta\left[\alpha-c^{u}-c^{d}\right]-\gamma\left[\alpha-a-c^{r}-s\right]\right]^{2}\right\} .
\end{gathered}
$$

Differentiating (A4.1) with respect to $s$ provides:

$$
\begin{gathered}
\pi^{I * /}(s) \stackrel{s}{=} \gamma\left[2 \beta\left(\alpha-c^{u}-c^{d}\right)-\gamma\left(\alpha-a-c^{r}-s\right)\right]-J\left[a-c^{u}\right], \text { and } \\
\pi^{I * / /}(s) \stackrel{s}{=} \gamma^{2} .
\end{gathered}
$$

Observation 4.1 follows from (A4.3), and Observation 4.3 follows from (A4.2) since (A4.2) is negative under the stated conditions. (

Proof of Observation 4.2.

From (A4.2) with $\gamma=\beta$ :

$$
\pi^{I * /}(s) \stackrel{s}{=} \alpha-c^{u}-2 c^{d}+c^{r}+s-2\left[a-c^{u}\right] .
$$

From (4.3) with $\gamma=\beta, q^{r *}>0$ if and only if:

$$
2\left[\alpha-a-c^{r}-s\right]>\left[\alpha-c^{u}-c^{d}\right] \text {, or }
$$




$$
-2\left[a-c^{u}\right]>2 c^{r}+2 s+c^{u}-c^{d}-\alpha .
$$

Substituting (A4.5) into (A4.4) yields:

$$
\pi^{I * /}(s) \stackrel{s}{=} 3\left[c^{r}+s-c^{d}\right] .
$$

Thus, $\pi^{I * /}(s)>0$ when $c^{r} \geq c^{d}$ and $s$ is below the level that forecloses firm $r$ (i.e., $s<\bar{s}$, so that $q^{r *}>0$ and (A4.5) holds as a strict inequality). Since $\pi^{I *}(s)$ is strictly increasing for $s<\bar{s}$, it follows that $s^{*}=\bar{s}$.

\section{Proof of Observation 4.4.}

Let $\Delta \equiv \pi^{I *}(0)-\pi^{I *}(\bar{s})$. The foreclosure level of sabotage $\bar{s}$ is defined by $q^{r *}=0$. Therefore, from (4.3):

$$
\bar{s}=\frac{1}{2 \beta}\left\{2 \beta\left[\alpha-a-c^{r}\right]-\gamma\left[\alpha-c^{u}-c^{d}\right]\right\} .
$$

When the integrated producer undertakes the foreclosure level of sabotage, its profit is:

$$
\pi^{I *}(\bar{s})=\left.\left[P^{d}\left(q^{d *}, 0\right)-c^{u}-c^{d}\right] q^{d *}\right|_{\bar{s}} .
$$

Substitution from (4.2), (4.4), and (A4.7) into (A4.8) provides:

$$
\pi^{I *}(\bar{s})=\frac{1}{4 \beta}\left[\alpha-c^{d}-c^{u}\right]^{2} .
$$

It follows from (4.2) - (4.4), (4.6), and (A4.9) that:

$$
\begin{aligned}
\Delta=\beta\left\{\frac { 1 } { J ^ { 2 } } \left[2 \beta\left(\alpha-c^{d}-c^{u}\right)\right.\right. & \left.\left.-\gamma\left(\alpha-a-c^{r}\right)\right]^{2}-\frac{1}{4 \beta^{2}}\left[\alpha-c^{d}-c^{u}\right]^{2}\right\} \\
+ & {\left[a-c^{u}\right] q^{r *}(0) }
\end{aligned}
$$

where, from (4.3):

$$
\left.q^{r *}(0) \equiv q^{r *}\right|_{s=0}=\frac{1}{J}\left[2 \beta\left(\alpha-a-c^{r}\right)-\gamma\left(\alpha-c^{u}-c^{d}\right)\right] .
$$


Let $y \equiv\left[2 \beta\left(\alpha-c^{u}-c^{d}\right)-\gamma\left(\alpha-a-c^{r}\right)\right] / J \quad$ and $\quad y_{0} \equiv\left[\alpha-c^{u}-c^{d}\right] / 2 \beta$. Therefore, because

$y^{2}-y_{0}^{2}=2 y_{0}\left[y-y_{0}\right]+\left[y-y_{0}\right]^{2}$, the first of the two terms in (A4.10) can be written as:

$$
\frac{\gamma}{4 \beta} q^{r *}(0)\left[\gamma q^{r *}(0)-2\left(\alpha-c^{u}-c^{d}\right)\right]
$$

Substituting (A4.11) and (A4.12) into (A4.10) and simplifying provides:

$$
\begin{gathered}
\Delta=\frac{\beta^{2} q^{r *}(0)}{4 J} h(\theta), \text { where } \theta \equiv \frac{\gamma}{\beta} \in[0,1], \text { and } \\
h(\theta) \equiv \theta^{3}\left[\alpha-c^{u}-c^{d}\right]+2 \theta^{2}\left[\alpha-a-c^{r}\right]-8 \theta\left[\alpha-c^{d}-c^{u}\right]+4\left[a-c^{u}\right]\left[4-\theta^{2}(\mathrm{~A}\right.
\end{gathered}
$$

Hence $\Delta \stackrel{s}{=} h(\theta)$ for $\theta \in[0,1]$. If $h(\theta)>0$, then $s^{*}=0$; while if $h(\theta)<0$, then $s^{*}=\bar{s}$.

Notice that $h(0)=16\left[a-c^{u}\right]>0$. Therefore, $s^{*}=0$ when $\theta=0$ (as stated in Observation 4.3). Furthermore, since $\gamma=\beta$ if and only if $\theta=1$ :

$$
\begin{aligned}
h(1) & =-7\left[\alpha-c^{d}-c^{u}\right]+2\left[\alpha-a-c^{r}\right]+12\left[a-c^{u}\right] \\
& =-5\left[\alpha-c^{d}-c^{u}\right]+2\left[c^{d}-c^{r}\right]+10\left[a-c^{u}\right] \\
& \leq 5\left[2\left(a-c^{u}\right)-\left(\alpha-c^{d}-c^{u}\right)\right] .
\end{aligned}
$$

The inequality in (A4.15) holds because $c^{r} \geq c^{d}$. From (A4.5) with $s=0$ :

$$
2\left[a-c^{u}\right]<\left[\alpha-c^{d}-c^{u}\right]+2\left[c^{d}-c^{r}\right] \leq \alpha-c^{d}-c^{u} .
$$

Substituting (A4.16) into (A4.15) yields $h(1)<0$, so $s^{*}=\bar{s}$ when $\theta=1$ (as Observation 4.2 implies). Moreover, differentiation of (A4.14) provides:

$$
\begin{aligned}
& h^{\prime}(\theta)=\left[3 \theta^{2}-8\right]\left[\alpha-c^{u}-c^{d}\right]+4 \theta\left[\alpha-a-c^{r}\right]-8 \theta\left[a-c^{u}\right] \\
& \leq\left[4 \theta^{2}-8\right]\left[\alpha-c^{u}-c^{d}\right]+4 \theta\left[\alpha-a-c^{r}\right]-8 \theta\left[a-c^{u}\right]
\end{aligned}
$$




$$
\begin{aligned}
& \stackrel{s}{=}\left[\theta^{2}-2\right]\left[\alpha-c^{u}-c^{d}\right]+\theta\left[\alpha-a-c^{r}\right]-2 \theta\left[a-c^{u}\right] \\
& \leq-\left[\alpha-c^{u}-c^{d}\right]+\left[\alpha-a-c^{r}\right]-2 \theta\left[a-c^{u}\right] \\
& =-\left[c^{r}-c^{d}\right]-[1+2 \theta]\left[a-c^{u}\right]<0 .
\end{aligned}
$$

Inequality (A4.19) holds because $\theta \leq 1$ so $\theta^{2}-2 \leq-1$. Inequality (A4.20) holds because $a>c^{u}, \quad c^{r} \geq c^{d}$, and $\theta \geq 0$. Therefore, $h(\theta)$ is strictly decreasing on $[0,1]$. Since $h(0)>0$ and $h(1)<0$, there exists aunique $\tilde{\theta} \in(0,1)$ (i.e., a unique $\tilde{\gamma} \in(0, \beta))$ such that $s^{*}=0$ for $\gamma<\tilde{\gamma}$ and $s^{*}=\bar{s}$ for $\gamma>\tilde{\gamma}$

\section{Proof of Observation 4.5.}

Notice from (A4.14) that $\operatorname{limit}_{\theta \rightarrow-\infty} h(\theta)=-\infty, \operatorname{limit}_{\theta \rightarrow \infty} h(\theta)=+\infty$, and $h(0)=16\left[a-c^{u}\right]>0$. Therefore, since $h(\cdot)$ is a cubic function of $\theta$ and since $\left.h^{\prime}(\theta)\right|_{\theta=0}=-8\left[\alpha-c^{u}-c^{d}\right]<0$, it follows from (A4.14) and (A4.17) that the non-monotonicity cited in Observation 4.5 will occur if and only if the largest root of $h(\theta)$ is strictly less than unity. It can be verified that the largest root of $h(\theta)$ is strictly less than unity when, for example, $\alpha=10, c^{u}=0, c^{d}=9, c^{r}=7.7575$, and $a$ $=0.2525$. These parameter values ensure that $\Delta$ is positive but close to zero at $\theta=1$ (i.e., at $\gamma$ $=\beta$ ) and declines below zero as $\theta$ is reduced below unity. As noted in the text, these parameter values ensure that $q^{r *}(0)$ declines as $\theta$ declines below unity. 


\section{REFERENCES}

Beard, T. R.; Kaserman, D.; and Mayo, J. 2001. Regulation, vertical integration, and sabotage. Journal of Industrial Economics 49(September): 319-333.

Bernheim, B. D., and Willig, R. 1996. The scope of competition in telecommunications. Monograph prepared for the AEI Studies in Telecommunications Deregulation.

Bulow, J.; Geanakoplos, J.; and Klemperer, P. 1985. Multimarket oligopoly: strategic substitutes and complements. Journal of Political Economy 93(June): 488-511.

Bustos, A., and Galetovic, A. 2003. Vertical integration and sabotage in regulated industries. Working paper. Princeton, NJ: Princeton University.

Cremér, J.; Rey, P.; and Tirole, J. 2000. Connectivity in the commercial internet. Journal of Industrial Economics 48(December): 433-472.

Dixit, A. 1986. Comparative statics for oligopoly. International Economic Review 27(February): 107-122.

Economides, N. 1998. The incentive for non-price discrimination by an input monopolist. International Journal of Industrial Organization 16(May): 271-284.

Faulhaber, G. 1987. Telecommunications in turmoil: technology and public policy. Cambridge, MA: Ballinger Publishing Company.

Hinton, P.; Zona, J. D.; Schmalensee, R.; and Taylor, W. 1998. An analysis of the welfare effects of long-distance market entry by an integrated access and long-distance provider. Journal of Regulatory Economics 13(March): 183-196.

Kang, J., and Weisman, D. 2001. Incentives for discrimination when upstream monopolists participate in downstream markets. Journal of Regulatory Economics 20(September): 125-140.

Kondaurova, I. and Weisman, D. 2003. Incentives for non-price discrimination. Information Economics and Policy 15(June): 147-171.

Lee, S. H., and Hamilton, J. 1999. Using market structure to regulate a vertically integrated monopolist. Journal of Regulatory Economics 15(May): 223-248.

Mandy, D. 2000. Killing the goose that may have laid the golden egg: only the data know whether sabotage pays. Journal of Regulatory Economics 17(March): 157-172.

Mandy, D., and Sappington, D. 2001. Incentives for sabotage in vertically-related industries. Working paper. Columbia, MO: University of Missouri. 
Milgrom, P. and Roberts, J. 1990. Rationalizability, learning, and equilibrium in games with strategic complementarities. Econometrica 58(November): 1255-1277.

Reiffen, D. 1998. A regulated firm's incentive to discriminate: a reevaluation and extension of Weisman's result. Journal of Regulatory Economics 14(July): 79-86.

Sibley, D., and Weisman, D. 1998a. The competitive incentives of vertically integrated local exchange carriers: an economic and policy analysis. Journal of Policy Analysis and Management 17(Winter): 74-93.

Sibley, D., and D. Weisman. 1998b. Raising rivals' costs: the entry of an upstream monopolist into downstream markets. Information Economics and Policy 10( December): 451-470.

Topkis, D. 1995. Comparative statics of the firm. Journal of Economic Theory 67(December): 370401.

Vickers, J. 1995. Competition and regulation in vertically related markets. Review of Economic Studies 62(January): 1-17.

Vives, X. 1984. Duopoly information equilibrium: Cournot and Bertrand. Journal of Economic Theory. 34(October): 71-94.

Vives, X. 1990. Nash equilibrium with strategic complementarities. Journal of Mathematical Economics 19(July): 305-321.

Vives, X. 1999. Oligopoly pricing: old ideas and new tools. Cambridge, MA: The MIT Press.

Weisman, D. 1995. Regulation and the vertically integrated firm: the case of RBOC entry into interLATA long distance" Journal of Regulatory Economics 8(November): 249-266.

Weisman, D. 1998. The incentive to discriminate by a vertically-integrated firm: a reply. Journal of Regulatory Economics 14(July): 87-91.

Weisman, D. 1999. Vertical integration and exclusionary behavior in network industries. Working paper. Manhattan, KS: Kansas State University.

Weisman, D., and Williams, M. 2001. The costs and benefits of long-distance entry: regulation and non-price discrimination. The Review of Industrial Organization 18(May): 275-282. 